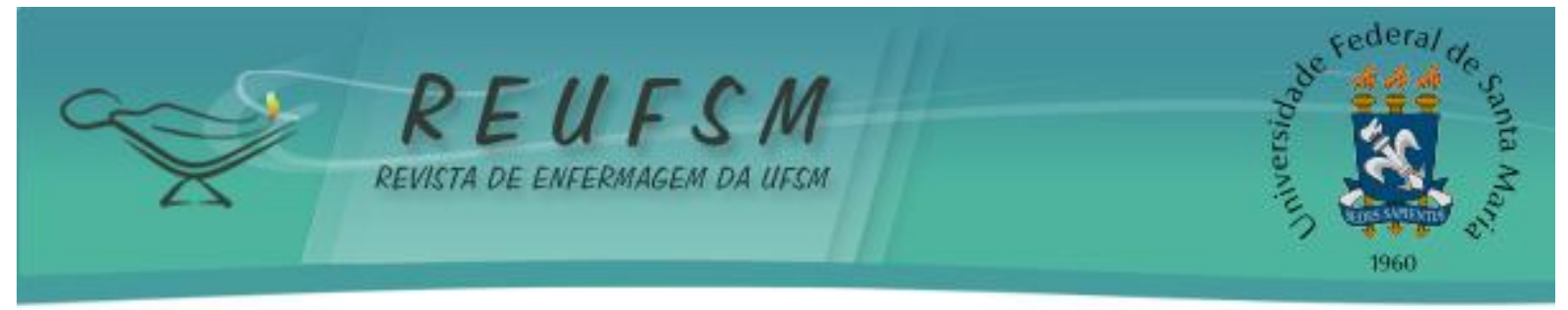

ARTIGO DE REVISÃO

\title{
O ENFERMEIRO E A EDUCAÇÃO EM SAÚDE: UM ESTUDO BIBLIOGRÁFICO
}

THE NURSE AND HEALTH EDUCATION: A BIBLIOGRAPHIC STUDY

EL ENFERMERO Y LA EDUCACIÓN EN SALUD: UN ESTUDIO BIBLIOGRÁFICO

\author{
Lenise Dias da Silva ${ }^{1}$ \\ Carmem Lúcia Colomé Beck ${ }^{2}$ \\ Caliandra Marta Dissen ${ }^{3}$ \\ Juliana Petri Tavares ${ }^{4}$ \\ Maria de Lourdes Denardin Budó ${ }^{5}$ \\ Hélio Soares da Silva ${ }^{6}$
}

RESUMO: Objetivo: investigar como os enfermeiros atuantes na atenção básica, realizam a educação em saúde com os usuários. Método: foi realizada uma pesquisa bibliográfica com abordagem descritivo-exploratória em artigos nacionais nas bases de dados LILACS e BDENF. Resultados: de acordo com critérios de inclusão e exclusão, 24 artigos foram selecionados e submetidos à análise temática. Os dados foram organizados em dois eixos temáticos: Educação em Saúde Emancipatória e Educação em Saúde Não Emancipatória. Conclusões: é relevante aprofundar as discussões sobre este tema, assim como indicar que os enfermeiros utilizem metodologias pedagógicas que respeitem a autonomia dos usuários, capazes de auxiliá-los no seu processo de aprendizado, no sentido de tornarem-se sujeitos do seu processo de viver.

Descritores: Enfermagem; Educação em saúde; Papel do profissional de enfermagem; Atenção primária à saúde.

ABSTRACT: Objective: investigate how nurses working in primary care, conduct health education with the users. Method: we performed a literature search with descriptive and exploratory approach in national articles in the databases LILACS and BDENF. Results: according to the inclusion and exclusion criteria, 24 articles were selected and subjected to thematic analysis. Data were organized into two main themes: Health Education and Health Education Emancipation and Health Education Not Emancipation. Conclusions: it is important to deepen discussions on this theme as well as indicate that nurses use teaching methods that respect the autonomy of the users are able to assist them in their learning process, to become subjects of their life process.

Descriptors: Nursing; Education in health; Nurse's role; Primary health care.

\footnotetext{
${ }^{1}$ Enfermeira. Graduada na Universidade Federal de Santa Maria/UFSM-RS. Aluna da Residência Multiprofissional em Saúde da Escola de Saúde Pública de Porto Alegre-RS. E-mail: lenise.dias@gmail.com

${ }^{2}$ Doutora em Enfermagem. Docente Associado do Departamento de Enfermagem da Universidade Federal de Santa Maria/UFSM-RS. Vice-Líder do Grupo de Pesquisa Trabalho, Saúde, Educação e Enfermagem da UFSM/Brasil. E-mail: carmembeck@gmail.com

${ }^{3}$ Acadêmica do Sétimo Semestre de Enfermagem da Universidade Federal de Santa Maria/UFSM - RS. Membro do Grupo de Pesquisa Trabalho, Saúde, Educação e Enfermagem da UFSM/Brasil. Bolsista PIBIC/CNPq. E-mail: kalidissen@yahoo.com.br

${ }^{4}$ Enfermeira. Doutoranda em Enfermagem na Universidade Federal do Rio Grande do Sul. Bolsista CAPES. Membro do Grupo Interdisciplinar de Saúde Ocupacional (GISO). E-mail: jupetritavares@gmail.com

${ }^{5}$ Doutora em Enfermagem. Docente Associado do Departamento de Enfermagem da Universidade Federal de Santa Maria/UFSM-RS. E-mail: lourdesdenardin@gmail.com

${ }^{6}$ Enfermeiro. Docente do curso de Enfermagem da Universidade do Estado do Rio Grande do Norte - UERN. Especialista em Ativação de Processos de Mudança na Formação Superior de Profissionais de Saúde. E-mail: helio_rn2001@yahoo.com.br
} 


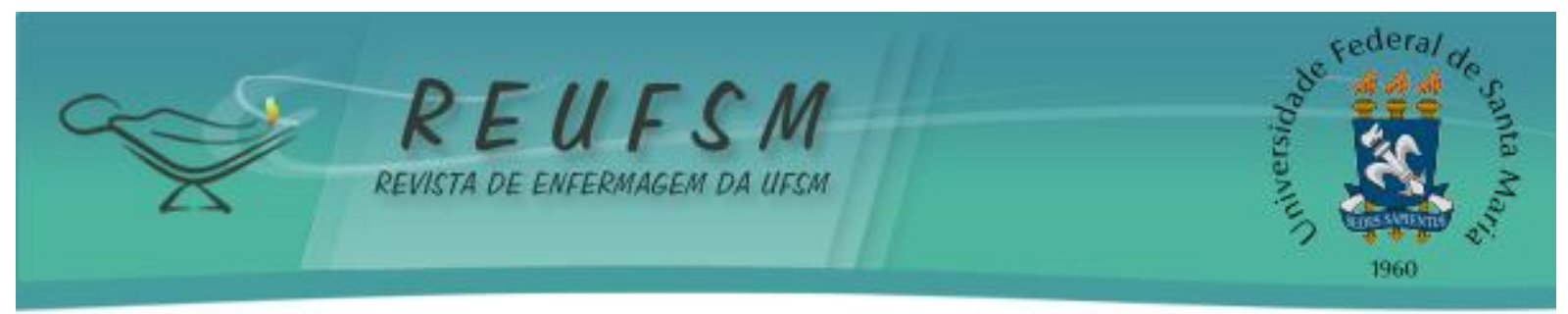

RESUMEN: Objetivo: investigar cómo los enfermeros actuantes en la atención primaria, realizan la educación para la salud con los usuarios. Método: fue realizada una búsqueda bibliográfica, de carácter exploratorio-descriptivo, en artículos nacionales con bases de datos LILACS y BDENF. Resultados: de acuerdo con criterios de inclusión y exclusión, 24 artículos fueron seleccionados y sometidos al análisis temático. Los datos fueron organizados en dos ejes temáticos: Educación en Salud Emancipatoria y Educación en Salud No Emancipacitoria. Conclusiones: es importante profundizar las discusiones sobre este tema, así como indicar que los enfermeros utilizan métodos de enseñanza que respete la autonomía de los usuarios y que sean capaces de ayudar en su proceso de aprendizaje con el fin de convertirse en sujetos de su proceso de vida.

Descriptores: Enfermería; Educación en salud; Rol de la enfermera; Atención primaria de salud.

\section{INTRODUÇÃO}

$\mathrm{Na}$ atenção primária, o enfermeiro desenvolve ações de gerenciamento, assistenciais e de educação em saúde, em todas as fases do desenvolvimento humano ${ }^{1}$, o que é reafirmado pelo Código de Ética dos Profissionais de Enfermagem. ${ }^{2}$ Portanto, o profissional de enfermagem deve participar de atividades que visem satisfazer as necessidades de saúde da população e da defesa dos princípios contidos nas políticas públicas de saúde e ambientais, estimulando a universalidade de acesso aos serviços de saúde, a integralidade da assistência, a resolutividade, a preservação da autonomia dos usuários, a participação da comunidade nas decisões relativas à saúde, a hierarquização e a descentralização político-administrativa dos serviços de saúde. ${ }^{2}$

Por ser um profissional voltado ao cuidado, o enfermeiro também tem como função estabelecer uma relação singular com cada usuário, família e comunidade e realizar ações de educação em saúde, na busca da construção compartilhada de conhecimento. Este processo deve incluir o diálogo, considerar e valorizar as vivências do usuário, contribuindo para a prevenção de doenças e para a promoção da saúde.

A educação em saúde é caracterizada como um processo com princípios críticos e reflexivos e metodologia baseada em diálogo, formando atores sociais integrados e participativos, especialmente, nas questões de gestão da saúde. ${ }^{3}$ Assim, a educação em saúde pode auxiliar na compreensão das causas dos problemas de saúde da comunidade, bem como na busca de soluções para os mesmos. ${ }^{4}$

A educação é um processo permanente que pode se constituir como prática que conduz a políticas de intervenção social e que pode ter associada uma metodologia problematizadora. ${ }^{5}$ Nesse processo, "o respeito à autonomia e à dignidade de cada um, é um imperativo ético e não um favor que podemos ou não conceder uns aos outros". 5:35 Assim, educar não é transferir conhecimento, é uma forma de intervenção no mundo e, sendo assim, exige do educador respeito aos saberes do educando e à sua autonomia, liberdade e criatividade. A disponibilidade verdadeira para o diálogo é essencial e, nessa perspectiva, a educação tem uma relação íntima com a saúde. ${ }^{5}$ De acordo com a perspectiva freireana, tem-se a educação em saúde como um processo, e como tal, está sempre em construção. Essa construção de conhecimentos deve ocorrer na relação dialogada entre profissionalusuário buscando nas vivências, o ponto de partida da prática educativa.

Dessa forma, faz-se necessário vislumbrar o profissional de enfermagem como um ator político-social, ou seja, um agente no processo de mudança social. Acredita-se que, por meio da educação em saúde como método de ensino dialógico, o enfermeiro pode aprender a respeitar e potencializar a autonomia do usuário na luta por melhores condições de saúde.

Portanto, com ênfase na atuação dos enfermeiros relacionada às ações de educação em saúde e tendo ressaltada a importância de tais ações para a assistência 


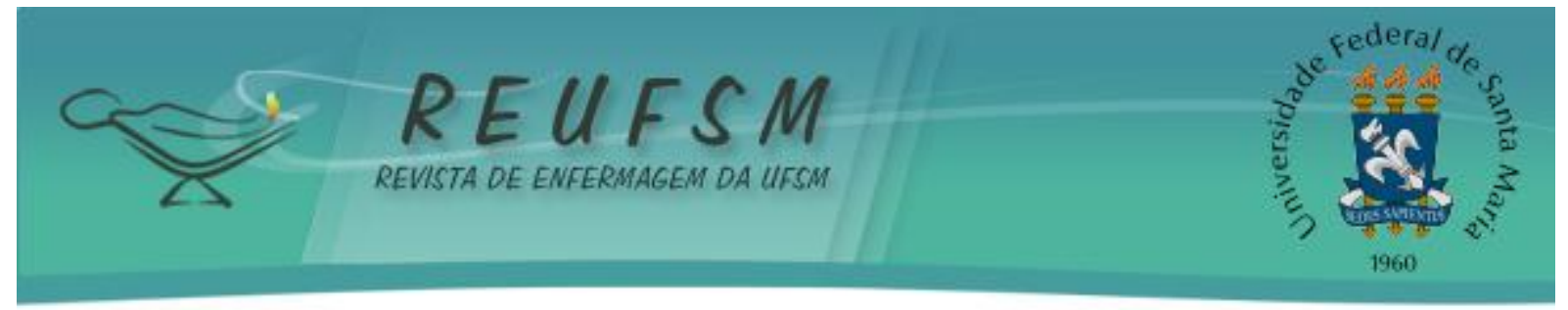

adequada aos usuários, realizou-se uma busca sistematizada de estudos publicados que apresentassem o tema de educação em saúde na enfermagem. Assim, o objetivo desse estudo foi investigar como os enfermeiros, atuantes na atenção básica, realizam a educação em saúde com usuários, a partir de publicações em periódicos.

\section{MÉTODO}

Este estudo apresenta uma pesquisa bibliográfica, com abordagem exploratóriodescritiva, a partir da leitura de artigos científicos na área de enfermagem e atenção básica. A pesquisa bibliográfica, com base em material publicado, tem a vantagem de permitir uma cobertura ampla dos fenômenos estudados, bem maior do que a possibilidade que o pesquisador teria de investigar diretamente. ${ }^{6}$

O levantamento bibliográfico dos artigos foi realizado a partir da consulta em duas bases de dados: Literatura Latino-Americana e do Caribe em Ciências da Saúde (LILACS) e Base de Dados de Enfermagem (BDENF), no mês de maio de 2011. Para tal, utilizou-se o termo "educação em saúde" associado, dois a dois, com os seguintes descritores: atenção primária à saúde, enfermagem, papel do profissional de enfermagem, cuidados de enfermagem, enfermagem em saúde comunitária e enfermagem em saúde pública.

Os textos encontrados foram selecionados pela leitura do título e resumo, sendo que estes deveriam atender a problemática da pesquisa, ou seja, os objetivos propostos no estudo na realidade brasileira.

Após a identificação dos resumos, considerou-se como critério de exclusão a não disponibilidade online do texto completo, publicação que não fosse artigo científico como teses ou livros e artigos escritos por outros profissionais que não enfermeiros. Na busca pelos textos, não foi estipulado o ano como critério para inclusão ou exclusão, na tentativa de selecionar um número maior de artigos.

Após a leitura dos artigos, optou-se por excluir da análise àqueles que tratavam de pesquisas bibliográficas, pois os dados obtidos nestes estudos não evidenciavam, explicitamente, o trabalho realizado pelos enfermeiros.

A tabela 1, a seguir, ilustra o número de artigos selecionados conforme os descritores associados, bases de dados consultadas e critérios de inclusão e exclusão.

Tabela 1: Número de estudos selecionados, utilizando descritores associados em duas bases de dados e que atendessem aos critérios de inclusão e exclusão.

\begin{tabular}{|c|c|c|}
\hline \multirow[b]{2}{*}{ DESCRITORES ASSOCIADOS } & \multicolumn{2}{|c|}{$\mathrm{N}^{\circ} \mathrm{DE}$ RESUMOS } \\
\hline & LILACS & BDENF \\
\hline "educacão em saúde" e "atencão primária à saúde" & 208 & 30 \\
\hline $\begin{array}{c}\text { "educação em saúde" e "papel do profissional de } \\
\text { enfermagem" }\end{array}$ & 10 & 4 \\
\hline "educação em saúde" e "enfermagem" & 96 & 56 \\
\hline “educação em saúde" e "cuidados de enfermagem” & 69 & 56 \\
\hline "educação em saúde" e "enfermagem em saúde comunitária" & 46 & 40 \\
\hline "educação em saúde" e "enfermagem em saúde pública” & 19 & 29 \\
\hline RESUMOS ENCONTRADOS & 448 & 215 \\
\hline RESUMOS SELECIONADOS & 93 & 61 \\
\hline ARTIGOS SELECIONADOS PARA ANÁLISE & 20 & 19 \\
\hline ARTIGOS REPETIDOS NAS DUAS BASES DE DADOS & \multicolumn{2}{|c|}{15} \\
\hline TOTAL DE ARTIGOS ANALISADOS & \multicolumn{2}{|c|}{24} \\
\hline
\end{tabular}




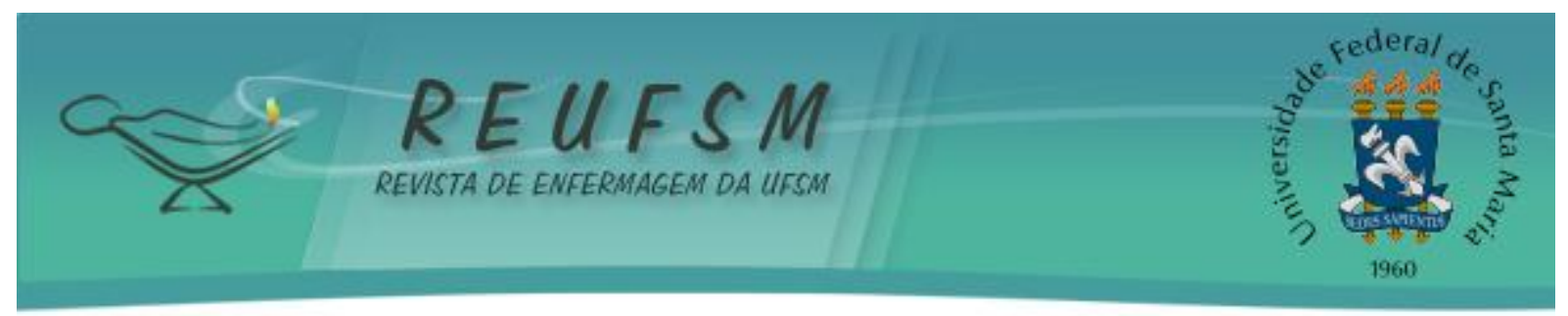

Após a seleção dos artigos, os mesmos foram lidos exaustivamente e submetidos à análise temática, uma das modalidades da análise de conteúdo, para descobrir os núcleos de sentido, os quais são as unidades de significação que compõem a comunicação, identificando a presença e frequência destes, para que assim surgissem as temáticas do estudo. ${ }^{7}$

Posteriormente à leitura exaustiva do material, foram identificados e agrupados os dados que se repetiam ou possuíam semelhança nos diferentes fragmentos em dois eixos temáticos. Depois, foi realizada a categorização dos elementos constitutivos de cada eixo destacando-se que, no decorrer da análise, foi identificada a repetição e homogeneidade dos dados.

Para organização dos dados foi elaborado um quadro sinóptico dos artigos, contendo o título, os autores, o periódico onde o artigo foi publicado, o ano da publicação, o tipo de pesquisa, os objetivos do estudo, os campos de desenvolvimento dos estudos e os resultados.

\section{RESULTADOS E DISCUSSÃO}

Por meio da análise dos artigos que apresentam a atuação do enfermeiro na educação em saúde, observou-se que a Região Sudeste concentrou o maior número de publicações, com 37,5\% ( $n=9)$, seguida das regiões Nordeste e Sul com $25 \%(n=6)$ das produções cada uma e da região Norte com 4,16\% ( $n=1)$. Dois artigos, o que corresponde a $8,3 \%(n=2)$, foram escritos em parceria entre duas ou mais regiões, um deles unindo as regiões Sul, Sudeste e Norte e outro englobando as regiões Sul e Nordeste.

Os textos analisados foram publicados nas revistas Texto \& Contexto de Enfermagem, Revista Brasileira de Enfermagem com 16,6\% ( $n=4)$ em cada uma; no Online Brazilian Journal of Nursing com 12,5\% ( $n=3)$ das publicações; nas revistas Interface, Cogitare Enfermagem, Revista de Enfermagem da UERJ (Universidade Estadual do Rio de Janeiro) e Revista Gaúcha de Enfermagem com 8,3\% ( $n=2)$ em cada um desses periódicos, seguidas da Revista de Enfermagem da Escola Anna Nery da UFRJ (Universidade Federal do Rio de Janeiro), Revista Ciência e Saúde Coletiva, Cadernos de Saúde Pública, Revista Mineira de Enfermagem e Revista Latino-Americana de Enfermagem com 4,16\% ( $n=1)$ em cada uma delas.

Todos os artigos foram escritos com a participação de professores universitários, por vezes acompanhados de acadêmicos de graduação ou mestrandos. Um percentual de 20,83\% ( $n=5)$ dos artigos teve a participação de enfermeiros que atuam na assistência de enfermagem e 4,16\% $(n=1)$ contaram com a participação de um psicólogo e de um cirurgião-dentista, um desses profissionais em cada artigo.

A maior parcela dos artigos apresentava reflexões teóricas e pesquisas qualitativas descritivas com 29,16\% $(n=7)$ cada categoria, seguidas de $25 \% \quad(n=6)$ por relatos de experiência; $12,5 \%(n=3)$ se tratavam de estudos transversais e 4,16\% $(n=1)$ das publicações se tratava de estudo caso-controle.

Em relação ao campo de desenvolvimento dos estudos, identificou-se que as instituições formadoras foram os ambientes que mais abarcaram estas atividades por meio de reflexões teóricas elaboradas sobre o tema com 29,1\% $(n=7)$ das publicações, seguidas pelas Unidades Básicas de Saúde com 20,83\% $(n=6)$. Todavia, os cenários de pesquisa foram variados, passando por escolas 16,6\% ( $n=4)$; Programas de Saúde da Família com 8,33\% $(n=2)$; Centro de Saúde, Programas de Atendimento ao Hipertenso, Unidades de Saúde, relato de Festival de Artes e Centro Desportivo com 4,16\% $(n=1)$ cada.

Os artigos analisados foram encontrados a partir do ano de 2003 , com 4,16\% ( $n=1)$, sendo que em 2004 houve o mesmo número de publicações 4,16\% (n=1); em 2005 e 2006 observou-se 8,33\% ( $n=2)$ das publicações em cada ano; em 2007 obteve-se a maioria dos artigos com 29,16\% ( $n=7)$; no ano de 2008, as publicações totalizaram 12,5\% (n=3); em 2009 foram publicados $20,83 \%(n=5)$ dos artigos e no ano de $2010,12,5 \%(n=3)$. 


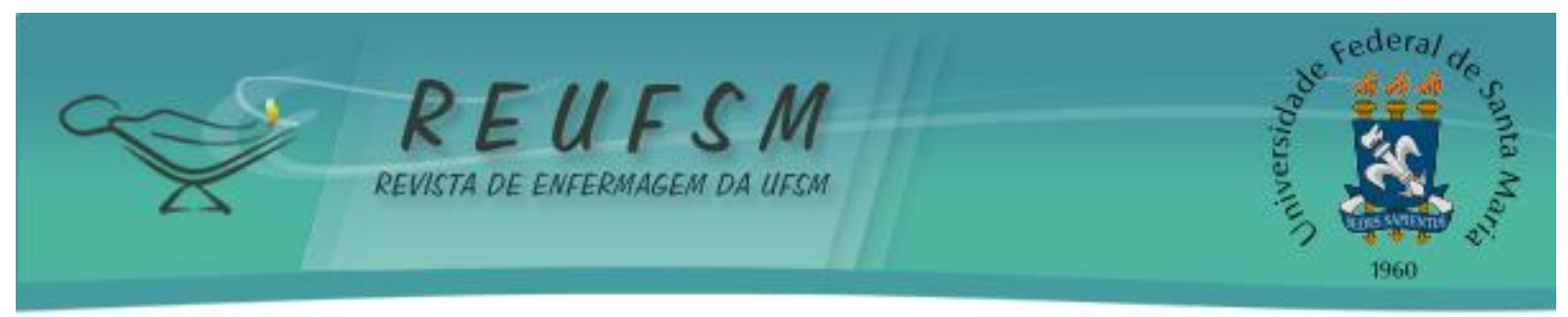

Considerando-se as abordagens utilizadas pelos profissionais enfermeiros, na perspectiva da análise temática, foi possível elencar dois eixos temáticos, os quais emergiram categorias, por semelhança, nos artigos avaliados.

0 primeiro eixo temático Educação em Saúde Emancipatória agregou categorias com ideias que se referem à utilização de metodologias emancipatórias, mais atuais, embasadas nos princípios do Sistema Único de Saúde (SUS) e na pedagogia freireana. 0 segundo eixo temático Educação em Saúde Não Emancipatória associou categorias com relatos de práticas e discursos não condizentes com uma perspectiva de emancipação, ou seja, como situações não desejáveis para a prática dos enfermeiros.

No eixo temático Educação em Saúde Emancipatória, duas categorias foram organizadas: educação em saúde como prática participativa, dialogada e reflexiva e educação em saúde com perspectiva problematizadora. Tais categorias se referem a pensamentos e ações de enfermeiros, relatados nos artigos, os quais demonstraram modos de fazer educação em saúde com uma perspectiva de promover emancipação dos usuários. ${ }^{8}$

Nesse sentido, a categoria educação em saúde como prática participativa, dialogada e reflexiva foi evidenciada na maioria dos trabalhos. Diversos autores afirmaram que a atividade educativa deve ser uma prática de diálogo, em que tanto os profissionais de saúde quanto os usuários tenham voz ativa na interpretação da realidade e na busca de mudanças para melhorar a qualidade de vida.

É imprescindível que a educação em saúde seja embasada em reflexão, pois é com o desenvolvimento de atitude crítica que a ação terá efetividade, sendo autônoma, na medida em que estimula o poder decisório do usuário. Além disso, a reflexão e a crítica podem transformar ou reconstruir saberes com a população, ao mesmo tempo em que também os apropria de conhecimentos populares. ${ }^{9}$

Acredita-se que a educação é um processo de construção de saber e, para tanto, é necessário a participação de todos os envolvidos, isto é, profissionais e usuários. Neste sentido, o diálogo deve ser central na postura do profissional de saúde, o qual precisa aprender a ouvir e respeitar, ao mesmo tempo em que deve expor o que sabe a respeito de determinado tema. ${ }^{4}$

A segunda categoria, educação em saúde deve ter perspectiva problematizadora, evidencia que as ações educativas devem partir da realidade dos usuários, de suas experiências, vivências e necessidades.

Para implementar certa prática educativa e esta ter eficiência, é essencial "conduzi-la conforme as percepções e potencialidades dos sujeitos para os quais se direciona a intervenção". ${ }^{10: 223} \mathrm{Em}$ um dos estudos sobre educação e saúde mental na família, foi relatado que as temáticas abordadas nos encontros com os sujeitos emergiram das sugestões do grupo, partindo da realidade e necessidade dos mesmos e contando com uma abordagem dialogada e participativa. ${ }^{10}$

Nesse sentido, de educação em saúde emancipatória, estudos ${ }^{11-13}$ ponderaram que o enfermeiro é um facilitador no processo educativo e que as ações educativas podem servir como suporte para as mudanças, uma vez que os profissionais não detêm a verdade absoluta, e, por meio de uma reflexão participativa, podem estimular a promoção da saúde individual ou grupal. Um desses estudos ${ }^{11}$ sinaliza ainda que a atuação do enfermeiro frente aos usuários deve ser de um facilitador, no sentido de orientar para que a tomada de decisão seja do usuário, desenvolvendo sua autonomia.

Considera-se que, seguindo essas premissas de diálogo, problematização, participação ativa do usuário e reflexão para ação, o processo de educação em saúde pode ser efetivo, produzindo mudanças na qualidade de vida e de saúde dos usuários.

No segundo eixo temático Educação em Saúde Não Emancipatória, emergiu a categoria modelo pedagógico verticalizado que se refere a pensamentos e ações de 


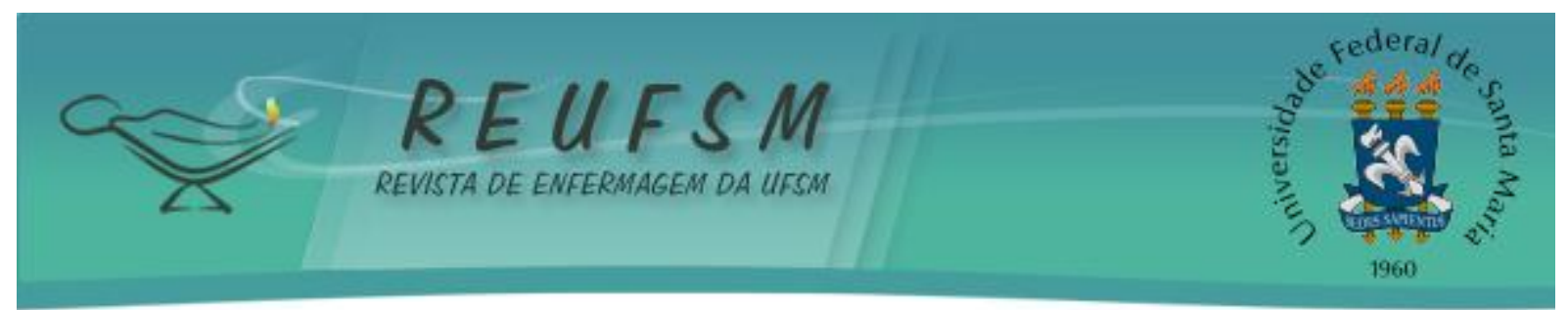

enfermeiros, relatados nos artigos, os quais demonstram ações educativas que não estão de acordo com uma prática emancipatória.

Nessa categoria observa-se que a grande parcela das práticas educativas desenvolvidas na saúde são impositivas, unidirecionais, reproduzindo o modelo biomédico de saúde que desconsidera a singularidade, o conhecimento popular e a autonomia dos usuários. ${ }^{8-9,12-13}$ Esse tipo de prática se dissocia do que é preconizado na perspectiva freireana, que ressalta que é preciso pensar na educação em saúde não como um processo de transferência de conhecimento de quem sabe para quem não sabe, mas como um processo constante e inacabado, de criação de possibilidades de produzir conhecimento, no qual haja respeito à autonomia do usuário e ele seja ativo. ${ }^{5}$

Nas atividades em grupos de saúde, por vezes os profissionais trabalham ressaltando o conhecimento técnico, no qual se baseia o modelo biomédico, buscando ressaltar normas e ordens técnicas da saúde. ${ }^{8}$ Dessa forma, evidenciam-se ainda práticas de saúde pautadas no modelo de educação linear, de metodologia depositária, a qual substitui o conhecimento popular pelo científico e na qual o educador, num sentido unidirecional, determina o programa de ensino para o grupo. ${ }^{9}$

Logo, as práticas de educação em saúde, na atualidade, ainda têm grande influência do modelo higienista do passado, sem que ocorra problematização, desconsiderando os saberes e a real necessidade popular. ${ }^{12}$ Além disso, são "poucos estudos que se debruçam sobre as práticas educativas". 12:118

Observou-se que algumas práticas descritas nos artigos remetem a ações impositivas e verticalizadas ao não problematizar, não considerar o contexto de vida dos usuários, não partirem da necessidade dos usuários ou entender que o saber parte do profissional de saúde para o usuário. ${ }^{14-16}$

Alguns destes estudos ${ }^{15-17}$ apresentaram uma prática de educação em saúde, referindo-se a atividades de orientações. Acredita-se que esta atividade é necessária e pode conduzir à educação de modo participativo, quando profissional e sujeito são ativos no processo educativo. Porém, considera-se que nos referidos artigos, há evidências que sugerem a realização de atividades de orientação feitas de modo impositivo, não respeitando a autonomia do usuário. Em um deles ${ }^{17}$, apesar das autoras relatarem uma prática educativa feita de forma dialogada e lúdica, observam-se sinais de uma metodologia verticalizada ao solicitarem para os sujeitos que relatassem o que lhes foi ensinado ou os pesquisadores ficarem satisfeitos ao observarem que eles sabiam repetir tudo o que havíamos falado.

Tendo por base os estudos analisados, percebe-se que alguns enfermeiros não têm uma concepção de educação em saúde como prática dialogada e problematizadora e assim, continuam reproduzindo o modelo tradicional com ações verticalizadas.

\section{ALGUMAS CONSIDERAÇÕES}

A partir da leitura dos artigos selecionados, pode-se afirmar que a concepção de educação em saúde, para alguns, caracteriza-se como um processo contínuo, de perspectiva problematizadora, baseado em diálogo e corrobora com as ideias pedagógicas freireanas, no qual o usuário deve ser sujeito, agente ativo da sua aprendizagem. Entretanto, alguns artigos abordaram atividades educativas em saúde com um enfoque biomédico, ou seja, uma transmissão verticalizada de saber que não condiz com a educação em saúde emancipatória, pois não estimula a reflexão dos sujeitos.

Assim, conforme encontrado na literatura pesquisada, os enfermeiros atuantes na atenção básica realizam educação em saúde de diferentes formas, por vezes tendo concepções e ações dialogadas, reflexivas e problematizadoras e, por vezes, trabalhando a 


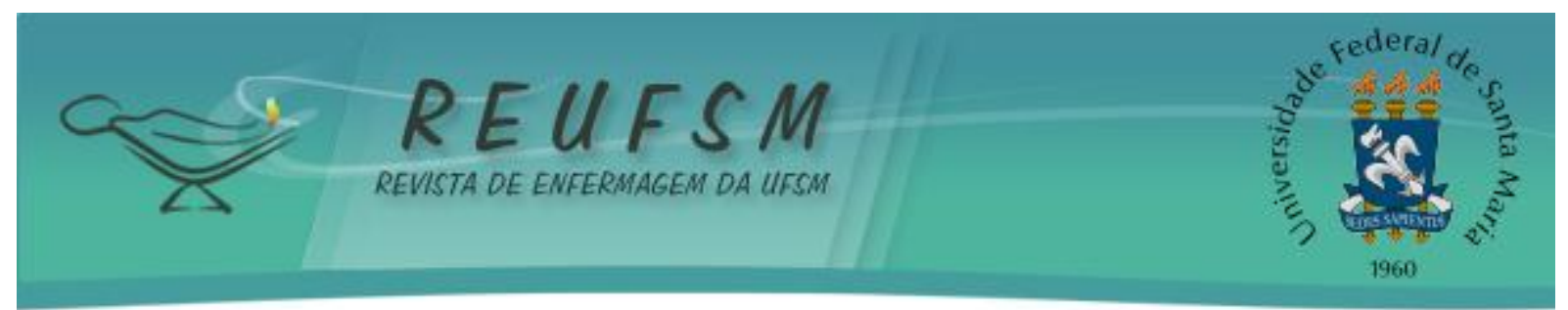

educação em saúde como se fosse uma prática de repasse de informações, reproduzindo o modelo pedagógico depositário.

Portanto, as discussões sobre o tema são indispensáveis, sendo urgente a efetivação da prática de educação em saúde emancipatória, para que deixe de ser uma teoria e se torne realidade no trabalho dos profissionais de saúde, em especial do enfermeiro atuante na atenção básica. Logo, este é um grande desafio para a profissão de enfermagem, a qual envolve características próprias de cada enfermeiro, bem como aspectos relacionados ao ensino realizado pelas instituições formadoras.

No que se refere à formação acadêmica, torna-se essencial repensar este processo, valorizando a educação em saúde como dispositivo para a promoção da saúde e a prevenção de doenças. A formação de enfermeiros, nesta perspectiva, pode ser um fator que contribua, efetivamente, para que esta prática se reproduza junto aos usuários, suas famílias e a comunidade em que estão inseridos.

\section{REFERÊNCIAS}

1. Brasil. Ministério da Saúde. Coordenação de Acompanhamento e Avaliação do Departamento de Atenção Básica da Secretaria de Políticas de Saúde do Ministério da Saúde. Informe da Atenção Básica: atuação do enfermeiro na atenção básica. n 16. Brasília: Ministério da Saúde, 2002.

2. Cofen. Resolução Cofen $n^{\circ} 311$, de 18 Jan de 2007, Código de Ética dos Profissionais de Enfermagem. [acesso em 2009 mai 10]. Disponível em http://www.portalcorenrs.gov.br/web/coren_legisla_E.php.

3. Brasil. Ministério da Saúde. Conselho Nacional das Secretarias Municipais de Saúde. O SUS de A a Z: garantindo saúde nos municípios. $3^{\mathrm{a}}$ ed. Brasília: Ministério da Saúde; 2009. 480 p.

4. Vasconcelos EM. Educação popular nos serviços de saúde. $3^{\text {a }}$ ed. São Paulo: Hucitec; 1997.

5. Freire $P$. Pedagogia da autonomia: saberes necessários à prática educativa. $36^{\mathrm{a}}$ ed. São Paulo: Paz e Terra; 1996.

6. Gil AC. Como elaborar projetos de pesquisa. $4^{\mathrm{a}}$ ed. São Paulo: Atlas; 2002.

7. Minayo MCS. $O$ desafio do conhecimento: pesquisa qualitativa em saúde. $10^{a}$ ed. São Paulo: Hucitec; 2007.

8. Souza FGM, Terra MG, Reibnitz KS, Backes VMS. Educação em saúde, enfermeiros e criatividade: a interconexão necessária para o processo educativo. Online braz j nurs [internet]. 2007 [acesso em 2009 out 23];6(2). Disponível em: <http://www.objnursing.uff.br/index.php/nursing/article/view/j.16764285.2007.829/223>

9. Alvim NAT, Ferreira MA. Perspectiva problematizadora da educação popular em saúde e a enfermagem. Texto \& contexto enferm. 2007;16(2):315-19.

10. Macedo VCD, Monteiro ARM. Educação e saúde mental na família: experiência com grupos vivenciais. Texto \& contexto enferm. 2006;15(2):222-30.

11. Acioli S. A prática educativa como expressão do cuidado em Saúde Pública. Rev bras enferm. 2008;61(1):117-21.

12. Beserra EP, Pinheiro PNC, Barroso MGT. Ação educativa do enfermeiro na prevenção de doenças sexualmente transmissíveis: uma investigação a partir das adolescentes. Esc Anna Nery Rev Enferm. 2008;12(3):522-8. 


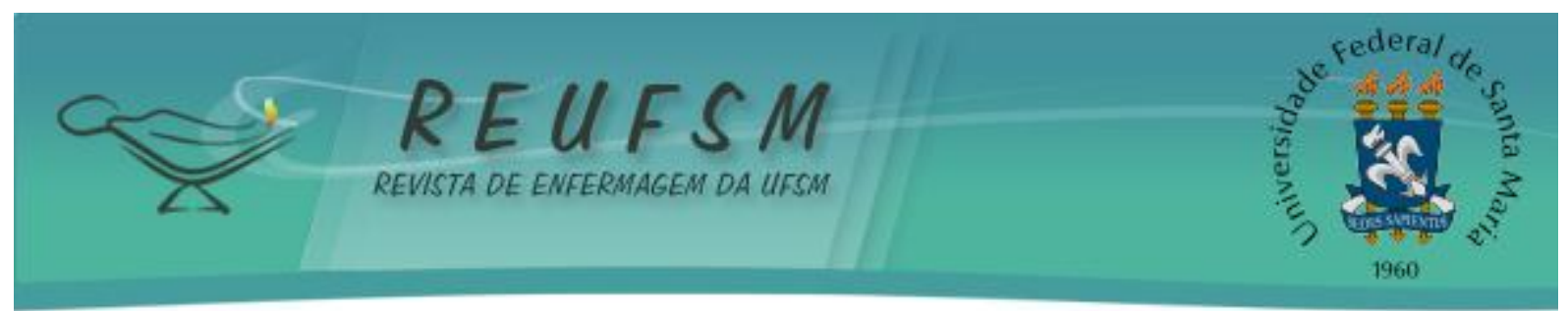

13. Erdmann AL, Nascimento KC, Silva GK, Ramos SL. Cuidado de enfermagem e educação em saúde com profissionais do surf. Cogitare enferm. 2007;12(2):241-7.

14. Rolim MO, Castro ME. Adesão as orientações fornecidas no Programa de Controle da Hipertensão: uma aproximação aos Resultados Padronizados de Enfermagem. Online braz j nurs [internet]. 2007 [acesso em 2011 ago 17];6(1). Disponível em: http://www.uff.br/nepae/siteantigo/otherissues.htm.

15. Oliveira HM, Gonçalves MJF. Educação em saúde: uma experiência transformadora. Rev bras enferm. 2004;57(6):761-3.

16. Mantovani MF, Mottin JV, Rodrigues J. Visita domiciliar de enfermagem com atividades educativas no tratamento da pressão arterial. Online braz J nurs [internet]. 2007 [acesso em 2011 ago 17];6(1). Disponível em:

http://www.uff.br/objnursing/index.php/nursing/article/view/757/171.

17. Bova VBR, Wall ML. Educação no trânsito: uma contribuição da enfermagem. Cogitare enferm. 2005;10(1):60-5.

Data de recebimento: $16 / 03 / 2011$

Data de aceite: 13/10/2011

Contato com autor responsável: Carmem Lúcia Colomé Beck

Endereço: Av. Roraima, n 1000, prédio 26, Centro de Ciências da Saúde (CCS), Departamento de Enfermagem, Bairro Camobi, Santa Maria-RS/Brasil.

CEP: $97105-900$

E-mail: carmembeck@gmail.com 